\title{
Correction to: Hind Foot Drumming: Muscle Architecture of the Hind Limb in Three Bathyergidae Species
}

\section{Sahd ${ }^{1} \cdot$ N. C. Bennett ${ }^{2} \cdot$ S. H. Kotzé ${ }^{1}$}

Published online: 24 November 2020

(C) Springer Science+Business Media, LLC, part of Springer Nature 2020

\section{Correction to: Journal of Mammalian Evolution} https://doi.org/10.1007/s10914-020-09527-4

The original article was published online with incorrect Fig. 2.

Please see below the correct image.

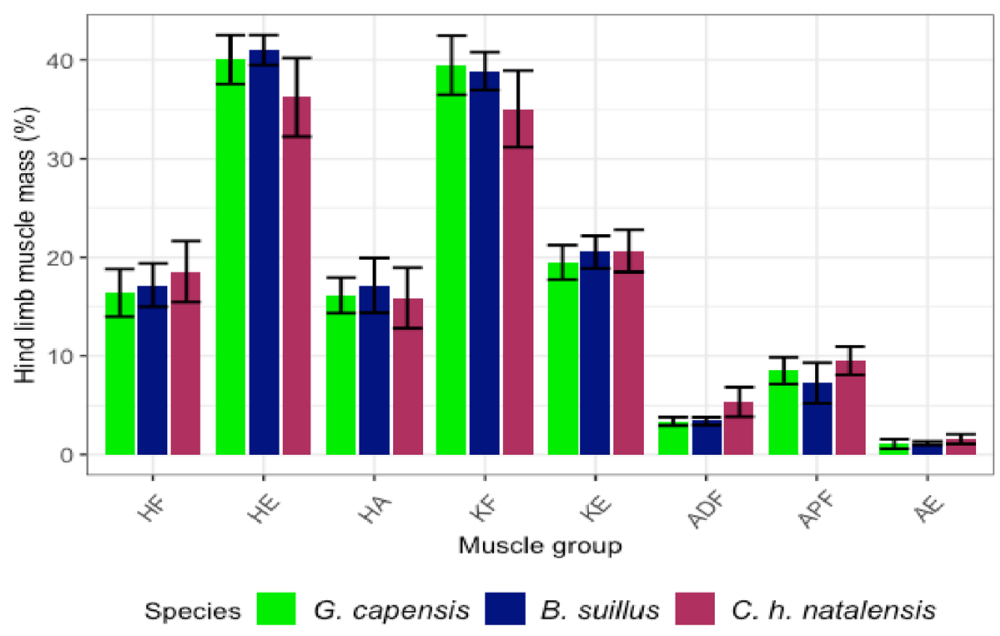

The online version of the original article can be found at https://doi.org/ $10.1007 / \mathrm{s} 10914-020-09527-4$

S. H. Kotzé

shk@sun.ac.za

1 Division of Clinical Anatomy, Department of Biomedical Sciences, Faculty of Medicine and Health Sciences, Stellenbosch University, PO Box 241, Cape Town 8000, South Africa

2 Mammal Research Institute, Department of Zoology and Entomology, University of Pretoria, Pretoria 0002, South Africa 